\title{
Biliary boulders
}

\author{
H Steed, ${ }^{1} \mathrm{~K}$ Lau, ${ }^{1}$ R Glass, ${ }^{1}$ D Durkin, ${ }^{2}$ M Deakin, ${ }^{2}$ J R B Green ${ }^{1}$
}

\begin{abstract}
${ }^{1}$ Department of Gastroenterology, University Hospital North Staffordshire, Stoke-on-Trent, Staffordshire, UK

${ }^{2}$ Department of Hepatobiliary Surgery, University Hospital North Staffordshire, Stoke-onTrent, Staffordshire, UK
\end{abstract}

\section{Correspondence to} Dr J R B Green, Department of Gastroenterology, University Hospital North Staffordshire, Stoke-on-Trent, Staffordshire, UK ST4 6QG:

jonathon.green@uhns.nhs.uk

Received 18 September 2013 Revised 22 November 2013 Accepted 10 December 2013 Published Online First 8 January 2014
To cite: Steed $H$, Lau $K$, Glass R, et al. Frontline Gastroenterology 2014;5:161-166.

\begin{abstract}
Objective To examine the outcome of endoscopic retrograde

cholangiopancreatography (ERCP) in the management of common bile duct (CBD) stones.

Design $A$ retrospective review of 100 consecutive ERCPs performed for CBD stones.

Results 100 ERCPs were performed on 84 patients with a median cohort age of 77 . Completion in this cohort, as defined by duct clearance, was achieved in $65 \%$ of cases. Completion rates fell rapidly after two ERCPs. $33 \%$ of the cohort had small stones $<10 \mathrm{~mm}$, and $67 \%$ had stones $>10 \mathrm{~mm}$. Size, but not number of stones, affected the completion rate and frequency of complications (16\%). Presence of periampullary diverticulum did not affect completion or complication rates. MR cholangiopancreatography (MRCP) had a 90\% sensitivity for detecting CBD stones compared with $56 \%$ for CT.
\end{abstract}

Discussion and conclusions ERCP remains a high-risk procedure with a significant complication rate when performed to deal with CBD stones. MRCP should be the second choice of investigation for CBD stones. This cohort had an unusually high number of larger stones at ERCP of $67 \%$ compared with other published UK cohorts of $8 \%$, and this was reflected in the completion and complication rate.

\section{BACKGROUND}

Common bile duct (CBD) stones are often the reason for performing a therapeutic endoscopic retrograde cholangiopancreatography (ERCP). Techniques in ERCP have improved over the past decade and studies report that $85-95 \%$ of all CBD stones can be effectively managed by conventional ERCP methods. ${ }^{12}$ This includes stenting in older patients with significant comorbidities. Incomplete CBD stone extraction can leave a patient at risk of recurrent cholangitis, gallstone pancreatitis and biliary obstruction, all of which are associated with a significant mortality and comorbidity in elderly patients. A large multicentre analysis showed that factors associated with incomplete ERCP include failed cannulation, Billroth II gastrectomy, CBD stone size and number and CBD stenting. ${ }^{3}$ Biliary stenting is often used when complete stone clearance is not successful, usually as a temporary measure, but in some cases as a permanent treatment. This is, however, associated with late complications (33.7\%); the risk increases proportionally over time and probably should be restricted to patients unfit for later elective treatment who have a short life expectancy. ${ }^{45}$ Although this is a common clinical problem, relatively few studies have been carried out on the characteristics of patients with CBD stones and the effectiveness of treatment by ERCP. This review was therefore undertaken to look at a consecutive series of patients undergoing ERCP for CBD stones in this large teaching hospital in North Staffordshire.

\section{METHODS}

All consecutive ERCPs were retrospectively reviewed between 1 August 2012 and 31 December 2012 at the University Hospital North Staffordshire, with review of relevant blood results, radiological investigations and discharge letters. ERCPs for pancreatic disease, biliary strictures alone or normal ERCPs where stones were not identified were excluded. ERCPs that directly involved CBD stones, but were part of a series of treatment ERCPs where the initial ERCP included CBD stones, were included.

Completion of the procedure is defined as successful stone extraction, complete clearance of duct and a clear cholangiogram after a duct trawl.

Stone size was assessed based on the endoscopist's report and clarification with radiological imaging. In those cases where the endoscopist had not estimated stone size, radiological imaging alone was used. In cases where the endoscopist had not given a stone size and the radiological 
images were unclear or contradictory, the result is recorded as unknown size.

\section{Statistics}

Groups were tested for Gaussian distribution, and normally distributed data were analysed with an unpaired $t$ test. If data failed the normality test they were analysed using the Mann-Whitney U test. Where more than two groups were compared, the KruskalWallis test was used.

\section{RESULTS}

\section{Demographics}

One hundred ERCPs, of 155 ERCPs in the time period, were performed on 84 patients with CBD stones. Sixty-one ERCPs were undertaken in women, 39 in men. The mean age of the patients was 76.2 years, range 39-93 years and median 77 years.

Thirteen patients had had previous cholecystectomies and 34 patients had been previously identified as having asymptomatic gallstone disease. Thirty-two procedures were performed as outpatient procedures, the remaining 68 as inpatient ERCPs on patients after emergency admission.

\section{Investigation before ERCP}

Sixteen per cent of patients did not have an ultrasound scan (US), the remaining $84 \%$ did. Results of imaging before ERCP are shown in table 1. Single modality radiological investigation before ERCP occurred in $48 \%$ of patients; of these $79 \%$ had an US, $15 \%$ underwent MR cholangiopancreatography (MRCP) and 6\% had a CT scan. Forty-five per cent of patients were investigated by two radiological modalities before ERCP. Of these, 90\% were investigated first with an US, $6.5 \%$ with an initial CT scan and $3.5 \%$ with initial MRCP. Only $7.2 \%$ of the whole group were investigated by three modalities before ERCP, all of which had US as their first modality.

Table 1 Imaging findings before ERCP in patients who had stones or microlithiasis on ERCP

\begin{tabular}{lcccc}
\hline \multirow{2}{*}{ Finding } & US & CT & MRCP & EUS \\
& $n=84(\%)$ & $n=24(\%)$ & $n=30(\%)$ & $n=2(\%)$ \\
\hline Nil seen & 2 & 0 & 0 & 0 \\
Sludge in GB & 6 & 0 & 3 & 0 \\
Normal CBD & 8 & 9 & 0 & 0 \\
GB stones+normal CBD & 13 & 9 & 0 & 0 \\
Dilated CBD only & 16 & 18 & 3 & 0 \\
CBD stones & 3 & 23 & 50 & 100 \\
CBD and GB stones & 16 & 23 & 40 & 0 \\
GB stones+dilated CBD & 35 & 18 & 3 & 0 \\
$\%$ Having investigation & 84 & 29 & 39 & 3 \\
\hline
\end{tabular}

CBD, common bile duct; $E R C P$, endoscopic retrograde cholangiopancreatography; EUS, endoscopic ultrasound; GB, gallbladder; MRCP, MR cholangiopancreatography; US, ultrasound.
In this cohort US had a sensitivity of $19 \%$, CT of $56 \%$ and MRCP $90 \%$ for the detection of CBD stones.

Of the 13 patients with gallbladder (GB) stones and a non-dilated CBD on US, all had further imaging before ERCP; nine out of these 13 patients had a CT scan and six out of these 13 patients had MRCP. Two-thirds of these CT scans showed the same findings as US; the remaining third showed GB stones with a dilated CBD. Where CT was a second-line investigation none of the scans showed CBD stones. All the second-line MRCPs showed GB and CBD stones.

Of the US scans in which a dilated CBD was the only finding, 90\% had further imaging; 40\% had CT, $60 \%$ had MRCP. All the MRCP scans showed CBD stones or CBD sludge, $25 \%$ of the CT scans were reported as a normal $\mathrm{CBD}, 50 \%$ showed $\mathrm{CBD}$ stones and $25 \%$ confirmed the US findings without adding anything to the clinical picture.

\section{Indication for ERCP}

The indications for ERCP were cholangitis in 17\%, abnormal imaging $10 \%$, pancreatitis $12 \%$, biliary pain with abnormal liver function test (LFT) 8\%, abnormal imaging and biliary pain and abnormal LFT 14\%, abnormal imaging and abnormal LFT 26\% and stent removal $8 \%$.

\section{Sedation}

The mean midazolam dose used was $3.28 \mathrm{mg}$ and the mean fentanyl dose $63.7 \mu \mathrm{g}$. All patients received lidocaine throat spray, the mean Buscopan dose was $17 \mathrm{mg}$ and three procedures were performed using propofol.

\section{Periampullary diverticulum}

Sixteen patients had a periampullary diverticulum (PAD); of these, nine $(56 \%)$ had a complete extraction at first ERCP. Of the incomplete extractions, 57\% (four patients out of seven) were referred for a second ERCP in this time period and the complete extraction rate of that group was $25 \%$ (one patient out of four patients).

\section{Sphincterotomy}

Sphincterotomy was performed or extended in 78 cases. Precut with a needle knife was required in six cases. In 24 of the procedures a sphincterotomy had been performed on a previous occasion. The data were unclear or unknown in three cases and the rest had iatrogenic undisrupted ampullae.

\section{Stone disease}

Thirteen ERCPs had no stones on the cholangiogram. However, they all had sludge and/or microlithiasis.

Table 2 shows the size of the largest stone found and the number of stones in the CBD at the time of 
Table 2 Size of the largest stone found and number of stones in the CBD at time of ERCP

\begin{tabular}{llccll}
\hline $\begin{array}{l}\text { No of } \\
\text { stones }\end{array}$ & $\begin{array}{l}\text { No of } \\
\text { patients }\end{array}$ & $<10 \mathrm{~mm}$ & $\begin{array}{l}10- \\
20 \mathrm{~mm}\end{array}$ & $>20 \mathrm{~mm}$ & Unknown \\
\hline Microlithiasis & 29 & - & - & - & - \\
0 & 13 & - & - & - & - \\
1 & 38 & 15 & 19 & 2 & 2 \\
2 & 8 & 0 & 7 & 1 & - \\
3 & 18 & 6 & 11 & - & 1 \\
Multiple & 20 & 5 & 13 & - & 2 \\
\hline
\end{tabular}

CBD, common bile duct; ERCP, endoscopic retrograde

cholangiopancreatography.

ERCP. In 50 procedures, stones between 10 and $20 \mathrm{~mm}$ were found and stones $>20 \mathrm{~mm}$ in three; in the rest, the stones were smaller at $<10 \mathrm{~mm}$ or of unknown size. Where more than one stone was found $(n=46)$, the largest stone was $>10 \mathrm{~mm}$ in $70 \%$ of cases.

\section{Stone extraction}

The duct was trawled with a balloon in 86 ERCPs, successfully extracting some or all stones in 75 cases (87\%). Three had basket trawls and two had mechanical lithotripsy, both of which were successful.

Eleven patients underwent sphincteroplasty; all had had a previous sphincterotomy. The four sphincteroplasties performed at the first ERCP were all successful at obtaining complete duct clearance. Six were performed at the second ERCP, with $40 \%$ complete duct clearance and one at the third, which was not successful. There was one unplanned admission after a sphincteroplasty, but no other sphincteroplasty-related complications.

Two of the three basket trawls successfully achieved complete clearance, and mechanical lithotripsy always led to a stent insertion and follow-up ERCP.

A biliary stent was inserted in 33 of the procedures, with an additional pancreatic stent in one patient when the pancreatic duct was unintentionally cannulated.

Completion, as defined in the 'Methods' section, was achieved in 65 of the 100 ERCPs during the study period-but not all patients had their first ERCP during this period. Analysis of completion in the 84 patients who had any of their ERCPs during the study period gives a truer reflection of the overall success and completion rates. For this cohort, at first ERCP $(\mathrm{n}=84)$ completion was $59 \%$, at second ERCP $(\mathrm{n}=19)$ completion was $53 \%$, at third ERCP $(n=4)$ completion fell to $24 \%$ and at fourth ERCP $(n=1)$ the procedure was incomplete. Overall, $73 \%$ of this cohort had complete duct clearance of their stones during the study period, the vast majority at the first ERCP.

Of the whole group of patients, $82 \%$ were deemed to have received definitive management at their first ERCP, which included stent insertion where complete stone extraction was not possible.

\section{Size of stones}

Where the size of the largest stone was recorded or measurable, difficulty of procedure (grade 1 or 2) could be assigned. ${ }^{16}$ Stone size was either recorded or measured on imaging review in 79 of the ERCPs. Twenty-six patients $(33 \%)$ had grade 1 stones-that is, microlithiasis or stone $<10 \mathrm{~mm}$; these patients had a mean age of 72 years. Grade 2 (stones $>10 \mathrm{~mm}$ in size) were present in $67 \%$ of patients-and this group were older with a mean age of 78.5 years $(p<0.01)$. Stone size was not recorded by the endoscopist in 21 of the ERCPs and measurements were based on radiological images reviewed after the procedure. Table 3 records the completeness of extraction achieved in the various grades of ERCP and how stone size affected the success of extraction in serial procedures. There was no significant difference in ERCP success rate for first, second and third procedures for small stones as a group or large stones as a group. However, the completion rates at first ERCP for grade 1 and grade 2 procedures were highly significantly different $(p<0.007)$ and this difference was maintained when all ERCPs in both groups were similarly compared $(\mathrm{p}<0.002)$.

\section{Complications}

Complications ${ }^{2}{ }^{7}$ occurred in 16 of the procedures. There were nine unplanned admissions, six episodes of bleeding (two transfused two units, two treated endoscopically, two self-limiting-no treatment required), four episodes of worsening cholangitis, four episodes of cardiovascular or respiratory compromise, one episode of pancreatitis, one perforation and one death within 30 days. The death was in a patient referred from the intensive therapy unit with severe sepsis due to cholangitis. Despite successful sphincterotomy and stent insertion, the patient did not recover.

Thirteen patients were readmitted within 30 days. Of those readmitted within 30 days, the cause was not directly related to the ERCP in two-one had congestive cardiac failure and one pulmonary embolus.

Table 4 shows complications in relation to stone size and number.

Table 3 Effect of size of stone on completion of endoscopic retrograde cholangiopancreatography $(E R C P)$, shown as complete duct clearance

\begin{tabular}{llll}
\hline & $\begin{array}{l}\text { Completion at } \\
\text { 1st ERCP (\%) }\end{array}$ & $\begin{array}{l}\text { Completion at } \\
\text { 2nd ERCP (\%) }\end{array}$ & $\begin{array}{l}\text { Completion at } \\
\text { 3rd ERCP (\%) }\end{array}$ \\
\hline Grade 1 (\%) & 73 & 80 & NA \\
Stones $<10 \mathrm{~mm}(\mathrm{n})$ & & 5 & \\
Grade 2 $(\%)$ & 36 & 37.5 & 0 \\
Stones $>10 \mathrm{~mm}(\mathrm{n})$ & & 16 & 3 \\
Unknown size (\%) & 57 & 0 & 100 \\
& & $\mathrm{n}=2$ & $\mathrm{n}=1$ \\
\hline
\end{tabular}




\section{Time to ERCP}

The time to inpatient ERCP for those admitted with biliary disease as a primary presenting complaint ranged from 1 to 24 days, with a median of 7 days.

\section{DISCUSSION}

This cohort had an unusually high prevalence of larger $\mathrm{CBD}$ stones compared with previously published series. ${ }^{1}$ Over two-thirds of patients in this series of consecutive patients referred for ERCP had CBD stones $>10 \mathrm{~mm}$, compared with only $8 \%$ in other published series. The reasons for this new and surprising finding are not known-the population of North Staffordshire, whose residents formed the study cohort, is a stable and genetically homogeneous population. The reasons may be genetic or acquired, including behavioural differences. Clearly, further study will be needed to inform this fascinating finding-including repeating the study in other areas of the UK to see if these results are replicated elsewhere.

With this unusually high percentage of large stones in the $\mathrm{CBD}$, it might be expected that ERCP might be technically more difficult, with a smaller percentage of complete duct clearance and a higher incidence of complications. In general, our study confirmed these expectations-thus validating stone size as one of the measures of degree of difficulty. However, there was another important difference in ERCP management of CBD stones between this study and other published studies; our patients-and specifically the patients with large CBD stones-were significantly older than those of previously published series. ${ }^{1}{ }^{2}$ In an area with high background levels of social deprivation, the comorbidities of these older patients would be a significant factor leading to potential complications. Although the incidence of complications seems high (and higher in the large-stone group), the outcome was good with no procedure-related mortality in this study.

It is also worth noting that the complication rate in this study is comparable to that reported in other large European studies, which reported a rate of $15.9 \% .^{78}$

Table 4 Frequency of complications in relation to number and size of stones.

\begin{tabular}{llll}
\hline No of stones & $\begin{array}{l}\text { Percentage of } \\
\text { patients with } \\
\text { complications }\end{array}$ & $\begin{array}{l}\text { Size of } \\
\text { stones }(\mathrm{mm})\end{array}$ & $\begin{array}{l}\text { Percentage of } \\
\text { patients with } \\
\text { complications }\end{array}$ \\
\hline 0 & 23 & $<10$ & 11.5 \\
1 & 16 & $10-20$ & 14 \\
2 & 25 & $>20$ & 33 \\
3 & 5 & Unknown & 20 \\
Multiple & 20 & & \\
\hline
\end{tabular}

This study also shows that the success rate of CBD clearance diminishes rapidly after two ERCPs. Numbers are small but the implication here is that patients should be carefully assessed before a third ERCP is scheduled. The need for regional biliary multidisciplinary team discussion and review is being considered nationally and this adds to that debate.

The completion rate (a topic of interest for the setting of quality assurance measures for ERCP) at the first ERCP in this study initially seems low (59\%) compared with other reports of $80 \% .^{1}{ }^{2}$ However, those studies were on patient groups with $92 \%$ grade 1 stones-compared with just $33 \%$ in our cohort. Although the Northern Regional Endoscopy Group report a completion rate of $62 \%$ for grade 2 difficulty ERCP (compared with $51 \%$ for our cohort), ${ }^{1}$ they include a definitive stent as a complete procedure. Also, their cohort was significantly younger (mean age 69)-as was the BSG Audit cohort (65 years). ${ }^{2}$ The overall completion rate of $73 \%$ of complete stone clearance in our entire group therefore compares well with the $80 \%$ completion reported in the other studies with much younger patients and with much smaller stones.

The British NCEPOD report of 2004 (National Confidential Enquiry into Patient Outcome and Death) raised the issue of appropriate patient selection for this high-risk procedure and prompted the 2007 British Society of Gastroenterology prospective audit. $^{2} 9$ Findings from both groups associated high American Society of Anesthesiologists (ASA) status ${ }^{10}$ with mortality. Although formal ASA status was not recorded in our study, the absence of any procedurerelated mortality in this elderly population with larger, more difficult stones suggests that patient selection is appropriate for this often prolonged, occasionally multistaged, interventional procedure. It is also reassuring that the relatively newly reintroduced technique of biliary sphincteroplasty (after papillotomy) appears both successful and safe in the study population.

The presence of a peri-ampullary diverticulum and its effect on the technical success and complication rate of ERCP continues to be a source of discussion. Although having a PAD did not affect our completion or complication rates, there is limited evidence as to the safety of balloon sphincteroplasty in the presence of PAD. PAD may associated with an increased incidence of large CBD stones and age. ${ }^{11}$ Sphincteroplasty in this group with or without sphincterotomy is reported to be as safe and effective as it is in those without $\mathrm{PAD}$, but future prospective studies focusing on an older cohort would be useful. ${ }^{11-13}$ Numbers in this study are too small to draw any meaningful conclusions about this point.

Complications associated with additional stone extraction techniques such as mechanical lithotripsy have been quoted as $4 \%$ in large studies. Of these, 
most can be resolved endoscopically, but $7 \%$ could not. ${ }^{14}$ Bearing in mind the older age of this cohort, the endoscopist must weigh up the risks and benefits for an individual patient. Many of these patients would not be suitable for surgery should the need arise from a complication. The small numbers of patients undergoing mechanical lithotripsy may reflect an individual preference for a stent and repeat procedure as the less risky of the two options.

Additionally, four episodes of cardiovascular or respiratory compromise occurred despite low levels of sedation. Again, this is likely to be reflective of the older age of the cohort, but would be prohibitive of additional sedation; this study does not explore the endoscopists' choice of risk in association with agitation. The evolution of propofol lists may see an improvement in duct clearance rates as they will allow for multiple interventions in one procedure.

For investigations carried out before performing ERCP, the American Society for Gastrointestinal Endoscopy standards of practice recommend that MRCP or endoscopic ultrasound is performed as the preferred second-line investigation. ${ }^{15}$ In this study, MRCP was by far the most effective second investigative choice, with CT having poor sensitivity for CBD stones. Altering the radiological referral pathway to include an early MRCP will probably considerably reduce any delay in diagnosis, time to ERCP, inpatient costs and morbidity.

Finally, the case mix of patients for ERCP at any particular centre could have important implications for training. Larger stones require the deployment of a larger range of therapeutic techniques. Centres with greater numbers of patients with 'large stones' are thus ideal for training at all levels of experience and are suitable for courses/demonstrations in an era of rapid change of ERCP accessories and techniques. Further studies of the continuing clinical challenge of CBD stones are needed.

In conclusion ERCP remains a high-risk procedure with a significant complication rate when performed to deal with CBD stones. The cohort of patients in

\section{Key messages}

- Endoscopic retrograde cholangiopancreatography (ERCP) remains a high-risk procedure for dealing with common bile duct (CBD) stones.

- Cohorts where larger stones predominate exist.

- Cohorts of larger CBD stones may see a higher complication rate and lower complete duct clearance rate.

- Rate of CBD clearance diminishes rapidly after two ERCPs.

- MRCP remains the most effective second investigative choice. this study has an unusually high number of patients with large CBD stones-and this is reflected in both the completion rate and the complication rate of the procedures. This patient population in North Staffordshire differs significantly from that of previous studies, being both older and having a very high percentage of patients with large stones. Reasons for this are not clear, but it is reassuring that, despite these larger stones, ERCP in this patient group seems to be both effective and safe.

Acknowledgements The authors thank the members of the endoscopy department for their assistance.

Contributors HS: design, data collection and analysis, drafting and revision of manuscript; KL, RG, DD and MD: data collection and revision of manuscript. JRBG: design, data collection and revision of manuscript.

Competing interests None.

Provenance and peer review Not commissioned; externally peer reviewed.

\section{REFERENCES}

1 Chatterjee S, Rees C, Dwarakanath AD, et al. Endoscopic retrograde cholangio-pancreatography practice in district general hospitals in North Easth England: a Northern Regional Endoscopy Group (NREG) study. J R Coll Physicians Edinb 2011;41:109-13.

2 Williams EJ, Taylor S, Fairclough P, et al. Are we meeting the standards set for endoscopy? Results of a large-scale prospective survey of endoscopic retrograde cholangiopancretograph practice. Gut 2007;56:821-9.

3 Williams EJ, Ogollah R, Thomas P, et al. What predicts failed cannulation and therapy at ERCP? Results of a large-scale multicenter analysis. Endoscopy 2012;44:674-83.

4 Kochief A, Gargouri D, Kilani A, et al. Retained common bile duct stones after endoscopic sphincterotomy: temporary and longterm treatment with biliary stenting. Tunis Med 2011;89:342-6.

5 Ang TL, Fock KM, Teo EK, et al. An audit of the outcome of long-term biliary stenting in the treatment of common bile duct stones in a general hospital. J Gastroenterol 2006;41:765-71.

6 Abbott RM. Grading of ERCPs by degree of difficulty: a new concept to produce more meaningful outcome data. Gastrointest Endosc 2000;51:535-9.

7 Cotton PB, Lehman G, Vennes J, et al. Endoscopic sphincterotomy complications and their management: an attempt at consensus. Gastrointest Endosc 1991;37:383-93.

8 Christensen M, Matzen P, Schulze S, et al. Complications of ERCP: a prospective study. Gastrointest Endosc 2004;60:721-31.

9 NCEPOD. Scoping our practice; the 2004 Report of the National Confidential Enquiry into Patient Outcome and Death. London: NCEPOD, 2004. http://www.ncepod.org.uk/ 2004.htm (accessed 3 Mar 2013).

10 Saklad M. Grading of patients for surgical procedures. Anesthesiology 1941;2:281-4.

11 Lee JW, Kim JH, Kim YS, et al. The effect of periampullary diverticulum on the outcome of bile duct stone treatment with endoscopic papillary large balloon dilatation. Korean J Gastroenterol 2011;58:201-7. 
12 Weinberg BM, Shindy W, Lo S. Endoscopic balloon dilation versus sphincterotomy for common bile duct stones. Cochrane Database Syst Rev 2006;4:CD004890.

13 Jeong S, Ki SH, Lee DH, et al. Endoscopic large-balloon sphincteroplasty without preceding sphincterotomy for the removal of large bile duct stones: a preliminary study. Gastrointest Endosc 2009;70:915-22.
14 Thomas M, Howell DA, Carr-Locke D, et al. Mechanical lithotripsy of pancreatic and biliary stones: complications and available treatment options collected from expert centers. Am J Gastroenterol 2007;102:1896-902.

15 American Society for Gastrointestinal Endoscopy. The role of endoscopy in the evaluation of suspected choledocholithiasis. Gastrointest Endosc 2010;71:1-9. 